\title{
Incorporating Systems Thinking into Local Governments in the United States of America
}

Author 1, ORCID: https://orcid.org/0000-0002-0573-6610

Author 1 Affiliation: Jennifer Capler, DM, University of Phoenix, Phoenix, AZ

SC Classification Genre: Public Administration

Creative Commons Attribution (c) (i) ()

Citation: Capler, J. (2021). Incorporating systems thinking into local governments in the United States of America. Scholar Chatter, 2(2), 22-29, http://doi.org/10.47036/SC.2.2.22-29.2021

(C) The Author. 2021. This is an open access publication through Scholar Chatter LLC.

\begin{abstract}
This is an opinion-based review of other research work on systems thinking paradigms and the possible application to local governments within the United States of America. Systems thinking is a complex interaction of people to generate thoughts, concepts, and ideas for situations involving organizational processes and changes. Using systems thinking can encourage collaboration, participative leadership, and interpersonal relations, increasing organizational effectiveness. Local government organizations may benefit greatly from creating and using systems thinking, incorporating constituent input before making decisions. Taking current organizational theory and design and recognizing a knowledge gap, this specific opinion-based review of using systems thinking emphasizes the importance of maintaining leadership and effective communication, advantages and disadvantages of system thinking paradigms, and ethical considerations. As communities grow and diversity expands, local government organizations should also grow and expand with the changing demands of constituents and economic needs. My theory is that with the incorporation of systems thinking, local government representatives can increase the overall effectiveness of council meetings and decision-making.
\end{abstract}

Keywords: Systems Thinking; Local Government Organizations; Effective Communication; Effective Decision-Making; Participative Leadership

\section{Introduction}

All organizations have some form of systems thinking. Systems thinking is a complex interaction of people to generate thoughts, concepts, and ideas for situations involving organizational processes and changes (Laware et al., 2006; Waldman, 2007). Creating a effective systems thinking paradigm in an organization can be complicated due to all the departments and personnel impacted by interrelated and yet separate situations (Poudehnad \& Bharathy, 2004). Using systems thinking can encourage collaboration, participative leadership, and interpersonal relations, all of which can increase organizational effectiveness (Brown, 2011; Greenwald, 2008; Jones, 2013; Scott \& Davis, 2007). People involved with an organizational systems thinking 
paradigm will have the ability to see the organization's larger vision and create long-term solutions to possible situations (Aronson, 1996).

This is an opinion-based review of previous research works on the effectiveness of systems thinking. I theorize that local government organizations (i.e., city council or Board of Aldermen) can benefit greatly from creating and using systems thinking. Many local government organizations in the U.S. function on a council/manager system with one representative for every separate area of a city and one mayor (Svara, 2003). All representatives can propose bills that require majority approval, passing as a law to help govern the city. Local government organizations generally conduct meetings every other week or once a month, where constituents can request to speak on items that are up for discussion regarding the proposal. On occasion, the representatives will ask to have studies conducted to determine the impact of certain proposals on constituents and the economy.

What is not conducted is a meeting within each representative's area, by the representatives themselves, to find out what their respective constituents desire before voting on proposals. In casual conversations with local government representatives within the St. Louis, Missouri metropolitan area, it has been expressed that attempting to conduct such meetings has been difficult due to a lack of attendance. In these casual conversations, representatives stated they were basing their evidence on the opinions of previous representatives.

This article presents a theory by creating a local government systems thinking paradigm. There is extensive human diversity in a city that is not being tapped into by local government organizations. Modern times have displayed the ease at which meetings can be conducted using technological advancements. Establishing a local government systems thinking paradigm that incorporates the constituents can improve the organizational function and decision-making process, improving the overall effectiveness of meetings (see Figure 1).

\section{Figure 1.}

Incorporating the Importance of Constituent Engagement Into the Proposed Local Government Systems Thinking Paradigm

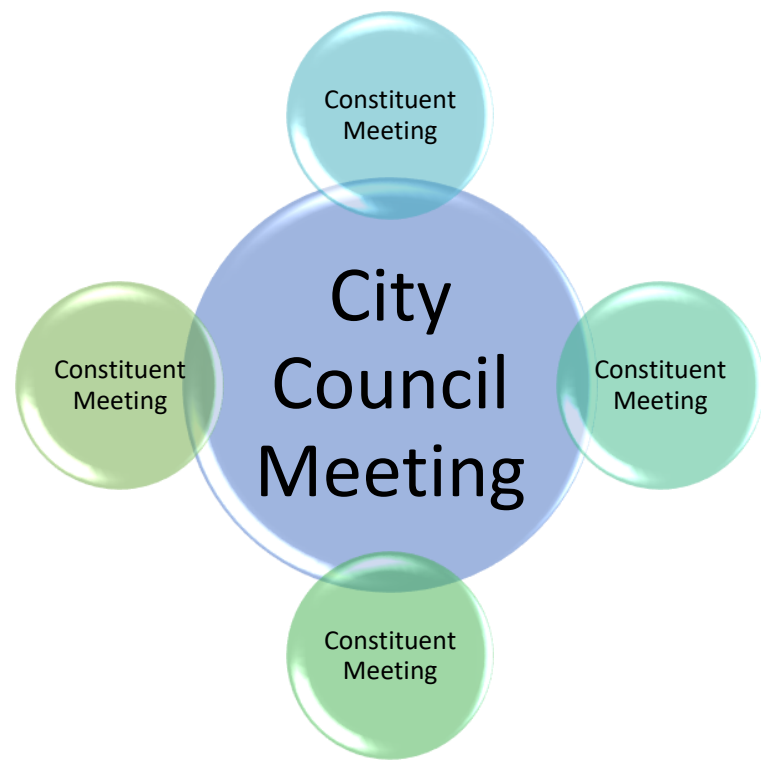


Conducting bi-monthly or monthly meetings in the center of a representative's area can provide an opportunity to hear new and diverse ideas, possible solutions, and present concerns over pending proposals. These meetings could allow for more work to be conducted by the representatives during regular meetings as fewer citizens will try to speak. Conducting meetings directly with constituents encourages community involvement and generates greater trust in the person elected as the representative.

The proposed theory of using systems thinking in local government organizations in the U.S. builds upon current organizational theory and design while recognizing a gap in current knowledge. Using systems thinking in local governments emphasizes the importance of maintaining leadership and effective communication while recognizing changing motivations for constituents. Advantages, disadvantages and ethics of using a systems thinking paradigm are important to consider when discussing the theoretical application in local government organization in the U.S.

\section{Review of the Literature}

\section{Organizational Theory and Design}

Many schools of thought about organizational theories and designs, range from classic perceptions to modern perceptions and future possibilities (Jones, 2013; Scott \& Davis, 2007; Tosi, 2009). Most organizational theories can be classified into seven areas (see Figure 2): closed system rational model, open system rational model, closed system natural model, open system natural model, integrative approaches, critical theory model, or postmodernism model (Scott \& Davis, 2007; Tosi, 2009). Many organizational theories and designs cater to large and complex organizations without mentioning how some smaller organizations can benefit greatly due to their complex nature, such as local governments.

Most organizations can and typically will have a drastic impact on the community in which it operates. Local government organizations, like the city council, have a direct impact on the local community, as the city council governs how a city will operate and establish local laws that citizens and other organizations must follow. There is a limited literature base to refer to regarding how organizational theory and design can aid local government organizations in the U.S. to be more effective. Most government organizations tend to rely on a closed system rational model, which do not always consider evolving human components or technological advances. There is also the factor that not every situation in a local government requires the same response. Taking into account the afore mentioned issues, and with a lack of proper research, it would be beneficial for a local government organizations to learn about all seven of the main areas of organizational theories to understand the appropriate time to apply each for the different situations.

Studies have been conducted in other countries, such as the United Kingdom and Italy, demonstrating the need to change government systems thinking paradigms which involves altering the organizational theory and design to accommodate future goals and interacting with changing constituent demands (Broccardo et al., 2019; Kamensky, 2013). There is a need to conduct more research studies on local government organizations within the U.S., providing a greater literature base for researchers. Further research could support lifelong learning and contributing that learning to the local government environment while exerting positive influence in academic, professional, and personal settings. In the meantime, it would be beneficial to use 
the information presented by foreign government research and apply that information locally. Many government representatives I have spoken with in casual conversations have rejected this notion based on the opinion that there is nothing wrong with current procedures. When asked if local governments are as effective as they were prior to growth, I typically get a response that indicates there is room for improvement. The complexity of large and diverse communities where constituents are supposed to be equally represented requires evolving and incorporating systems thinking.

\section{Figure 2.}

\section{Classes of Organization Theories}

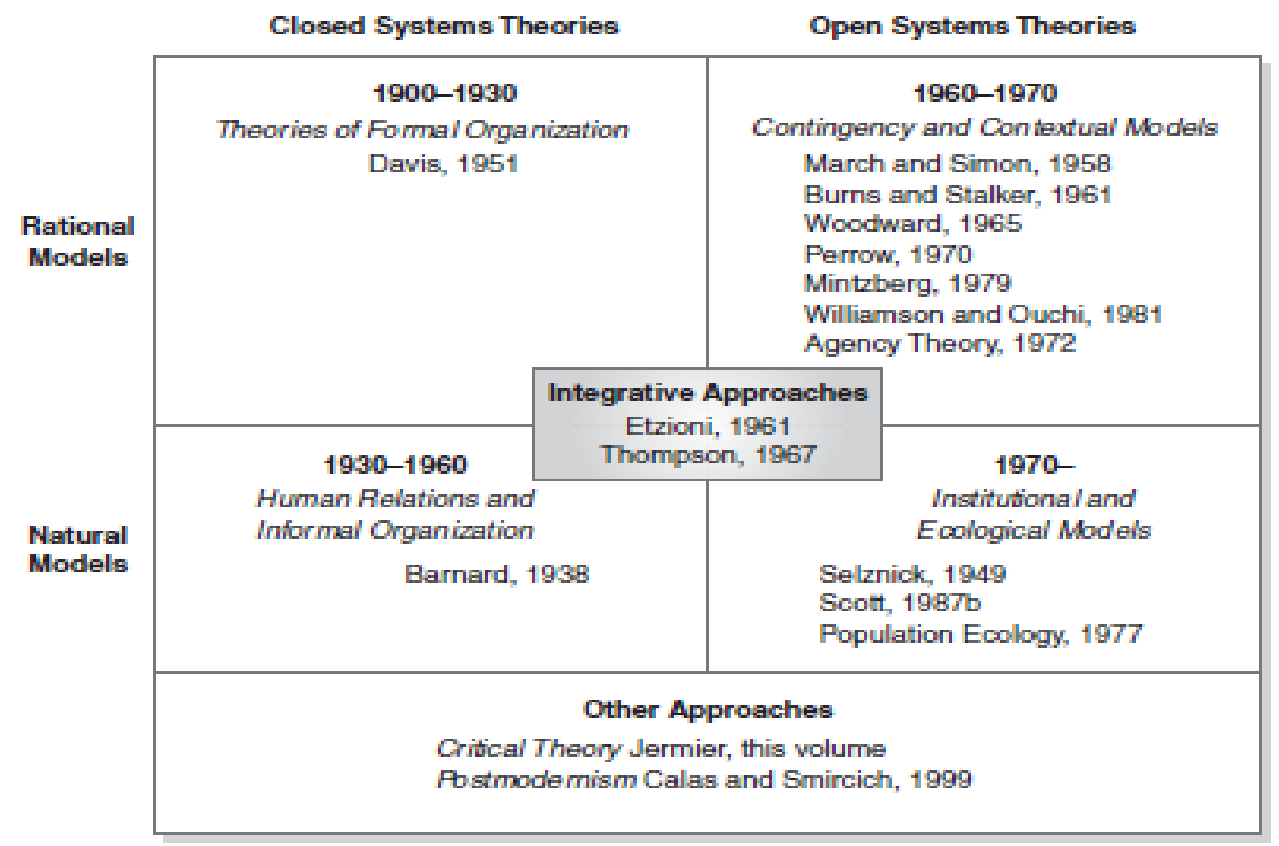

Note: Adapted from “Theories of Organization,” by H. L. Tosi, 2009. Copyright 2009 by Sage Publications

\section{Leadership and Communication}

Leadership and communication are important in local government organizations, such as city council. Leadership and communication are central concepts to creating a local government systems thinking paradigm. Councilmembers are expected to lead and communicate with their constituents in all matters, choosing the best options to build an economically viable city. When leadership and communication are not healthy in a city council, it can create an environment of poor reputation and little trust (Dandira, 2012).

Incorporating systems thinking into local governments requires strong leadership skills such as vision, goal setting, motivation, and excellent communication with constituents (Dandira, 2012). Change can be a scary notion to some people, but as communities grow and change, local government thinking process should also evolve. A strong city council leader can encourage change and alleviate tension through time, continual commitment, courage, and active listening (Dandira, 2012). 
Communication involves active participation, often seen as lacking in local government organizations (Crowder, 2017; Moon, 2016). Effective communication among local government and participants of a city will assist with incorporating systems thinking into local governments. Effective communication is important for incorporating systems thinking into local governments. There are many factors taken into consideration in the decision-making processes of local governments, some of which include constituent needs, other organizations within the community, and overall economics of the entire community (Svara, 2003). Representatives should be actively listening to others about various topics brought up, regardless of how that representative personally feels about the topic (Greenwald, 2008).

\section{Embracing Constituent Motivation}

People from all nations have basic, biological needs (physiological, safety, belongingness and love, esteem, and self-actualization) and constantly seek to satisfy those needs (Greenwald, 2008). While the premise of Maslow's Hierarchy of Needs does not change, how those needs are met has changed throughout history and organizational development (Kenrick et al., 2010). Local government representatives can motivate constituents to participate in the development of a systems thinking paradigm using more modern approaches to address constituents needs.

When conducting bi-monthly or monthly meetings, councilmembers can have a selection of snacks and drinks available, along with bathroom facilities, covering most immediate physiological needs. Meetings can be held in a centralized and familiar location that is well-lit and attended by security, accommodating the need for self-protection (Kenrick et al., 2010). Local government representatives can greet constituents and encourage participation through collaboration, acknowledging all ideas and thoughts from constituents. Acknowledging and encouraging participation and collaboration can provide a possible resolution to the need for affiliation and esteem needs. Covering most of the basic needs can encourage constituents to become more active and involved in local area meetings with their councilmember and the overall local government organization. The increase in collaboration and participation can then be applied to address other community needs, such as homelessness, violence, and economics. In turn, this can create greater support of local government representatives and organizations.

Technological advancements, such as Facebook and Zoom, have created another avenue for representatives to encourage constituent participation in meetings (Pittman, 2017). Not everyone is always available to attend meetings due to work and life conflicts. Using technological meeting rooms can make such meetings more available and easier for constituents with access. Technology can also be used to create polls where constituents can vote about how they feel about agenda items.

\section{Recommendation on Applying Systems Thinking in Local Government}

\section{Advantages and Disadvantages of Using Systems Thinking}

When looking at systems thinking paradigms, there are advantages and disadvantages. Some advantages of using systems thinking paradigms are creating an environment of collaboration, participative leadership, encouraging interpersonal relations, increased organizational effectiveness (Scott \& Davis, 2007). Encouraging a systems thinking paradigm can encourage collaboration among all organizational departments to determine better alternatives than what is currently practiced (Greenwald, 2008; Jones, 2013). Participative 
leadership encourages input from all departments, encouraging collaboration. Through collaboration and participative leadership, interpersonal relations are created among departments. All these components can create increased organizational effectiveness (Brown, 2011; Waldman, 2007).

There are also disadvantages when using a systems thinking paradigm, which can stem from the advantages. These can include unhealthy conflict, cognitive bias, cliques, information overload, and time consumption (Jones, 2013; Waldman, 2007). Unhealthy conflict can occur when departments fight what information to include in a systems thinking paradigm due to cognitive bias (Brown, 2011). There may be too much information to share, which can create a lag in the timely incorporation of systems (Greenwald, 2008).

\section{Ethical Considerations}

Ethics, socially reinforced values, can be a debatable topic, as not all unethical decisions are illegal, and one community can host a socially diverse group with differing values (Greenwald, 2008). In local government organizations, there is a greater emphasis to portray good ethical conduct, setting an example for the rest of a community. Incorporating systems thinking into local government organizations require contemplation about the ethical standards, taking into consideration that every group will have different standards. Other organizations within the community of the local government organization may demand to have their ethical standards adhered to, even if it is not a community-wide standard. A city council will have to weigh the legal recourses of different ethical concerns to determine if any constitutional rights or basic human rights may be hindered. The goal of creating a local government systems thinking paradigm is to have greater community involvement, which means the entire community and not just one group.

\section{Possibilities for Future Research Work}

Local government organizations tend to hesitate changing processes and procedures. Hesitation to change is somewhat understandable, given the relatively young age of the U.S. government system and the rapid increase of communities with diverse constituents. However, as a community grows, so does the need to change the systems thinking paradigm of local governments to incorporate the greater view of the needs and desires of diverse populations. Considering the ethical issues and the needs and desires of diverse populations, a local government can benefit by incorporating systems thinking by conducting bi-monthly or monthly meetings with constituents in each ward on proposed changes and community needs.

City council members are leaders of a community and can encourage change through positive action and effective communication. Action and communication can enhance city council meetings by decreasing the amount of time spent listening to all constituents at one time, in one location. In my opinion, incorporating systems thinking paradigm in local government organizations in the U.S. is needed for greater effectiveness. My opinion-based review of other research work on systems thinking paradigms as applied in various organizations could, theoretically, be applied to local government organizations within the U.S. This theoretical concept provides an opportunity to expand research on leadership effectiveness in local government organizations. Systems thinking research can add to what is currently a limited body of knowledge within U.S. government effectiveness. 


\section{Funding}

The authors received no financial support for the research, authorship, and/or publication of this article.

\section{References}

Aronson, D. (1996). Overview of systems thinking. http://www.stefanibardin.net/wpcontent/uploads/2017/01/Overview-of-Systems-Thinking.pdf

Broccardo, L., Culasso, F., \& Mauro, S. G. (2019). Smart city governance: Exploring the institutional work of multiple actors towards collaboration. International Journal of Public Sector Management, 32(4), 367-387. https://doi.org/10.1108/IJPSM-05-2018-0126

Brown, D. R. (2011). An experiential approach to organization development (8th ed.). PrenticeHall.

Crowder, D. (2017, March 20). Failing grades for city council: Mayoral candidates rate reps at forum. El Paso Inc. http://www.elpasoinc.com/news/local_news/failing-grades-for-citycouncil/article_01b0ca30-0d8a-11e7-b7d6-67fa8b95e07c.html

Dandira, M. (2012). Dysfunctional leadership: Organizational cancer. Business Strategy Series, 13(4), 187-192. https://doi.org/10.1108/17515631211246267

Greenwald, H. P. (2008). Organizations: Management without control. Sage Publications.

Jones, G. R. (2013). Organizational theory, design, and change (7th ed.). Prentice-Hall.

Kamensky, J. (2013, August 15). How to tackle complexity using systems thinking. Government Executive. http://www.govexec.com/excellence/promising-practices/2013/08/how-tacklecomplexity-using-systems-thinking/68795/

Kenrick, D. T., Griskevicius, V., Neuberg, S. L., \& Schaller, M. (2010). Renovating the Pyramid of Needs: Contemporary Extensions Built Upon Ancient Foundations. Perspectives on Psychological Science, 5(3), 292-314. https://doi.org/10.1177/1745691610369469

Laware, G., Davis, B., \& Peruisch, K. (2006). Systems Thinking: A paradigm for professional development. Journal of Modern Engineering, 6(2), 7-11.

https://ijme.us/issues/spring2006/p11.htm

Moon, J. (2016, January 7). Grafton citizens question motives of aldermen. The Alton Telegraph. https://www.thetelegraph.com/news/article/Grafton-citizens-question-motives-ofaldermen-12602279.php

Pittman, E. (2017, January 18). How technology is giving town hall meetings a modern twist. Government Technology. https://www.govtech.com/policy/how-technology-is-givingtown-hall-meetings-a-modern-twist.html 
Poudehnad, J., \& Bharathy, G. (2004, May). Systems thinking and its implications in organizational transformation [Conference Session]. ${ }^{\text {rd }}$ International Conference on Systems Thinking in Management, Philadelphia, PA, United States.

https://www.academia.edu/21794712/Systems_thinking_and_its_implications_in_organiz ational_transformation

Scott, W. R., \& Davis, G. F. (2007). Organizations and organizing: Rational, natural, and open systems perspectives. Prentice-Hall.

Svara, J. H. (2003). Effective mayoral leadership in council-manager cities: Reassessing the facilitative model. National Civic Review, 92(2), 157-172. https://doi.org/10.1002/ncr.14

Tosi, H. L. (2009). Theories of organization. Sage Publications.

Waldman, J. D. (2007). Thinking systems need systems thinking. Systems Research and Behavioral Science,24(3), 271-284. https://doi.org/10.1002/sres.828 